\title{
Development rule of temperature on oil-paper-insulated pin plate discharge under long-term operation Research
}

\author{
Zhao Zhong, Lu Xue
}

\begin{abstract}
In order to study the effect of temperature on the partial discharge of the oil-paper-insulated pin plate under long-term operation of the main transformer, we chose a vacuum heat aging 32-day simulation sample and a 28-year actual operation sample. And the step-up pressure method was used to test the local pressure of the needle plate of the two samples at ordinary temperature $\left(30^{\circ} \mathrm{C}\right.$, $\left.50^{\circ} \mathrm{C}\right)$ and high temperature $\left(85^{\circ} \mathrm{C}\right.$ signal point, $105^{\circ} \mathrm{C}$ trip point), and the relevant discharge characteristic quantity was analyzed by the partial discharge inspection instrument record.The results show:There is no significant difference between the heat-aged oil paper sample and the field sample in the early stage of discharge.However, there is a large difference in the development to the middle and late stages under the high temperature, especially the $105^{\circ} \mathrm{C}$ trip point; The maximum discharge and total discharge at ordinary temperature near the breakdown time are both small, which is $2 / 3$ of that at high temperature. The number of discharges gradually increased with the increase of compression time. The actual phase width and density of the actual samples at $105^{\circ} \mathrm{C}$ during the middle and late periods of discharge were higher than those of the simulated aging samples. That is to say, the influence of high temperature on the oil-paper insulation of the main transformer during long-term operation is greater than that at low temperature. The oil-paper insulation level actually collected at the site increases with the extension of the operating time. It is easier to enter a dangerous period than a laboratory simulation sample at high temperatures, and the consequences of partial discharge are more serious.
\end{abstract}

Index Terms - Heat aging, High and low temperature contrast, Heat aging, Needle plate discharge, Real and Simulation Oil paper insulation

\section{INTRODUCTION}

At present, $10 \mathrm{kV}$ to $500 \mathrm{kV}$ oil-immersed power transformers are one of the core equipment of the power grid, and their operating status always affects the safety, stability and reliability of the power system. Therefore, it is very important to find effective ways and methods to evaluate the early fault status inside the transformer[1-2]. Researchers usually use a simulation to establish an oil-paper insulation test platform to analyze the discharge characteristic of the resistance of the insulation paperboard, and use the test results to refer to and study the operating status of the transformer.

Zhao Zhong. Assistant Engineer of Xuzhou Power Supply Company of Jiangsu Power Company, Xuzhou, China.

China.
In recent years, researchers have done a lot of research on the mechanism and aging characteristics of oil-paper insulation partial discharge.R.J. Van Brunt et al. Studied the random characteristics of partial discharge and conducted an in-depth analysis[3]; R. Schifani of Italy carried out research on the amplitude distribution of partial discharge pulses of epoxy resin, and constructed two temperature conditions of $20^{\circ} \mathrm{C}$ and $80^{\circ} \mathrm{C}$, and studied the similarities and differences of discharge at different temperatures[4]; In addition, Yu Rui et al. Studied the development of white spots and discharge characteristics along the needle plate discharge[5]; $\mathrm{Wu}$ Guangning, Southwest Jiaotong University, etc, studied the difference in discharge between oil-paper insulation under different moisture contents[6]; Li Xining and others from Xi'an Jiaotong University analyzed the development law of discharge characteristic quantity under different AC/DC ratios[7]. At present, the judgment of the severity of partial discharge of oil-paper-insulated pin plates is mainly based on changes in the characteristic quantities of discharges from the initial discharge to the breakdown at normal temperature[8]-[9], Judging the running status of the transformer according to its online monitoring of the characteristic data of the main transformer discharge. However, in summer and other high-temperature weather, the oil temperature of the main transformer often reaches about $50^{\circ} \mathrm{C}$. If some defects occur, the oil temperature may be too high, and reaching the operating temperature point of the main transformer protection may cause serious accidents.

This article is different from previous studies. By collecting field oil-paper insulation samples from a recent $220 \mathrm{kV}$ main transformer when it is retrofitted to the plant for targeted aging simulation tests, needle plate discharge test of oil-paper insulation samples in actual operation for 28 years and simulated aging operation, respectively; In addition, the normal temperature of the transformer oil was selected to be $30^{\circ} \mathrm{C}, 50^{\circ} \mathrm{C}$ and high temperature $85^{\circ} \mathrm{C}$ (signal point), $105^{\circ} \mathrm{C}$ (trip point) for discharge test of oil-paper insulated pin plate. Study the differences between actual running cardboard samples and simulated aging cardboard samples in the tests. And we study the development law of the pin plate discharge of oil-paper insulation for long-term running transformers at high and low temperatures. The results have important reference and significance for judging the severity of the actual oil-paper-insulated pin plate discharge on site and the analysis and prevention and control of transformer operating conditions at different temperatures. 


\section{TEST PLATFORM AND METHOD}

\section{A. Design of test model and platform}

The experimental design is shown in Figure 1 for a typical pin plate discharge model.Among them, the electrode size is made in accordance with the IEC 60243 standard. The needle electrode material is metal tungsten, $\varphi=1 \mathrm{~mm}$, the needle tip curvature is $3^{\circ}$, and the low-voltage plate electrode size is $75^{*} 75^{*} 5 \mathrm{~mm}$.

Sample 1 is $80 \mathrm{~mm} \times 80 \mathrm{~mm} \times 2 \mathrm{~mm}$ insulating cardboard produced by a domestic manufacturer; Sample 2 is the internal oil-paper insulation sample of the main transformer collected on-site when a $220 \mathrm{kV}$ main transformer was returned to the factory recently. It has been running smoothly for 28 years. The surface of the cardboard sample is clean without traces of discharge and damage, and is directly packaged during collection to ensure that its microwater volume and vacuum state meet the standards.

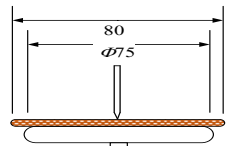

Fig.1 Needle plate discharge model

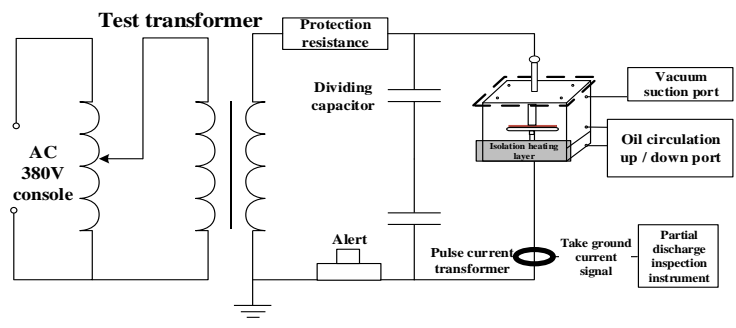

Fig.2 experimental platform

Figure 2 shows the schematic diagram of the oil paper insulation pin plate discharge test, including $\mathrm{AC}$ $380 \mathrm{~V}$ console, test transformer, analog transformer tank circulation system, alarm device, and partial discharge inspection instrument.The size of the tank of the analog transformer is $450 \mathrm{~mm} \times 300 \mathrm{~mm} \times 350 \mathrm{~mm}$. A heating device is installed at the bottom to control the oil temperature between room temperature and $120^{\circ} \mathrm{C}$, and it is covered with tempered glass to prevent accidental contact.Take an oil hole on the top and bottom of the fuel tank with oil control valve, connect to the two ends of the circulating oil pump through the hard oil pipe, and control the oil flow rate to $5 \mathrm{~L} / \mathrm{min}$ through the circulating oil pump; There is another air hole at the upper mouth to connect the vacuum pump to control the inside of the fuel tank to keep below 133pa;The ground wire is led out through the lower plate, and a pulse current transformer is installed on it to connect to the partial discharge inspection instrument to collect relevant discharge characteristic quantities.

\section{B. Cardboard sample selection and processing}

Sample one: Insulated cardboard produced by a domestic manufacturer was selected for simulated operation for 28 years.Use a vacuum drying box to carry out preliminary vacuum drying for 24 hours at a temperature of $90^{\circ} \mathrm{C} / 50 \mathrm{~Pa}$ and air pressure. After that, the micro-water meter was used to detect the micro-water volume fraction of the paperboard at $10.03 \times 10^{-6}$, which met the micro-water volume requirement of the test cardboard. Based on GB/T 7595-2008, we immersed the vacuum-dried cardboard in transformer oil after pure filter oil at a ratio of 1:10. Then seal it and put it in a vacuum heating box. Select the heat aging temperature as $\mathrm{T}=130^{\circ} \mathrm{C}$. Simulation calculation by Equation(1) based on Monsinger thermal aging rules[10]:

$$
T=T_{0} e^{-\alpha\left(\theta-\theta_{0}\right)}
$$

In the formula: $\theta$ is the actual operating temperature; $\mathrm{T}$ is the insulation life of $\theta ; \theta_{0}$ is the reference operating temperature, T0 is its insulation life; $\alpha$ has a thermal aging coefficient of 0.1155 . Therefore, we choose to aging for 32 days to simulate the actual state of oil-paper insulation for about 28 years.

Sample two: Select an oil-paper insulation sample collected from a $220 \mathrm{kV}$ main transformer running to the factory for transformation. Take oil samples through the oil inlet of the transformer, and then enter the inside of the transformer to collect samples of insulating cardboard when pumping oil through the main transformer below the manhole.Take oil samples through the oil inlet of the transformer; Then, when the oil is pumped to a low position, go inside the transformer to collect a sample of insulating cardboard. During the collection process, sealed bags are used to seal oil paper at a ratio of 10: 1 .

\section{Selection of temperature}

Because the oil temperature of the main transformer is usually around $50^{\circ} \mathrm{C}$ in summer, and its insulation life decreases with the increase of the operating time of the main transformer, it is likely to break through the signal temperature and trip point oil temperature set by the main transformer protection, which may seriously affect the substation. And the safety and reliability of the entire grid operation. Therefore, the conventional $30^{\circ} \mathrm{C}, 50^{\circ} \mathrm{C}$ and high temperature $85^{\circ} \mathrm{C}$ signal points and $105^{\circ} \mathrm{C}$ trip points were selected for the test. By comparing and analyzing the relevant characteristic quantities at variable temperatures, it provides a good reference for the online monitoring of partial discharges in transformers and for state assessment and accident prevention.

\section{D. experimental method}

We used a partial discharge tester to collect the relevant characteristic quantities and initial and breakdown voltages of two samples at four temperatures. First, the partial discharge instrument standard 100pc was calibrated by the calibrator to eliminate errors such as zero drift. After that, the AC $380 \mathrm{~V}$ control transformer is used to slowly increase the voltage in steps of $1 \mathrm{kV} / 30 \mathrm{~s}$ until the discharge signal appears, and it remains for about 10 minutes. If there is still a stable discharge signal, it is the initial discharge voltage U1. 
The experiment started from $1.2 \mathrm{U} 1$ with a step distance of $2 \mathrm{kV} / \mathrm{h}$ until the cardboard accessory ruptured, and the relevant feature quantities were collected every $5 \mathrm{~s}$. If there is still a stable discharge signal, it is the initial discharge voltage U1. Considering that the large discharge amount in the later period of pressure may cause the data to be blurred, the step size was changed to $0.5 \mathrm{kV} / \mathrm{h}$ when the discharge amount increased sharply and visible light and electricity appeared on the oil paper sample.In the experiment, each group of data was subjected to 4 consecutive experiments, and finally a relative comparison analysis was performed.

Table 1 shows the initial discharge voltage and breakdown voltage under the pin plate model. It can be known from Table 1 that the difference between the initial and breakdown voltages of the two paperboard samples is slightly smaller at the normal $30^{\circ} \mathrm{C}$ and $50^{\circ} \mathrm{C}$, and the field sample voltage value is slightly higher than the simulated sample at $30^{\circ} \mathrm{C}$. Under two severe temperature conditions of $85^{\circ} \mathrm{C}$ and $105^{\circ} \mathrm{C}$, it can be seen that the voltage value of the sample actually collected is significantly lower. At $105^{\circ} \mathrm{C}$, the simulated sample was broken down at $18^{\circ} \mathrm{C}$ to $18.5^{\circ} \mathrm{C}$ and maintained for about 10 minutes, while the on-site sample started to break down at $15.1^{\circ} \mathrm{C}$ every $0.5 \mathrm{kV} / \mathrm{h}$ step to $16.1^{\circ} \mathrm{C}$ and maintained for about 5 minutes. The results show that the gap between the simulated sample and the actual sample is slightly smaller at the normal temperature, and the actual sample is subjected to greater discharge hazards when the high temperature is severe. The test data of the simulated sample is different in terms of voltage under high temperature.

Tab.1 Initial discharge voltage and breakdown voltage

\begin{tabular}{|c|c|c|c|c|}
\hline \multirow{2}{*}{$\begin{array}{l}\text { temperat } \\
\text { ure } /{ }^{\circ} \mathrm{C}\end{array}$} & \multicolumn{2}{|c|}{$\begin{array}{c}\text { Initial discharge } \\
\text { voltage } / \mathrm{kV}\end{array}$} & \multicolumn{2}{|c|}{$\begin{array}{l}\text { Breakdown } \\
\text { voltage/kV }\end{array}$} \\
\hline & $\begin{array}{c}\text { Mock } \\
\text { sample }\end{array}$ & $\begin{array}{c}\text { Field } \\
\text { sample }\end{array}$ & $\begin{array}{c}\text { Mock } \\
\text { sample }\end{array}$ & $\begin{array}{c}\text { Field } \\
\text { sample }\end{array}$ \\
\hline 30 & 12.5 & 12.6 & 25.5 & 25.6 \\
\hline 50 & 12.3 & 12.0 & 25.3 & 24.9 \\
\hline 85 & 11.1 & 10.6 & $21.8 * 5 \mathrm{~min}$ & $21.5 * 0.5 \mathrm{~min}$ \\
\hline 105 & 9.8 & 9.3 & $18.5^{*} 10 \mathrm{~min}$ & $16.1 * 0.5 \mathrm{~min}$ \\
\hline
\end{tabular}

\section{PARTIAL DISCHARGE CHARACTERISTIC}

\section{COMPARISON}

Partial discharge inspection instrument is used to collect pulse current transformer transmission related data, and the recording interval is $5 \mathrm{~s}$. Matlab is used to process all relevant discharge characteristic quantities from initial pressurization to breakdown time to obtain the maximum discharge and average discharge for each time period (because the time of the later pressurization phase is less than $1 \mathrm{~h}$, the total discharge is not selected Quantity comparison), discharge time and phase spectrum. In the test, the simulated aging oil and paper sample is referred to as sample A, and the on-site oil and paper sample is referred to as sample B. The discharge characteristics of the two samples at different temperatures are analyzed. All experiments were performed three times and the results were averaged.

\section{A. Comparison of maximum discharge}

Figure 3 (a) and (b) show the development trends of the maximum discharge capacity of two samples at four temperatures,respectively.It can be seen from Figure 3 that in the first 1-2 hours of discharge, there is no significant difference in the discharge amount of each cardboard at four temperatures, all about 300pc; Beginning in the middle of $3 \mathrm{~h}$, the maximum discharge at the $105^{\circ} \mathrm{C}$ trip point increased the most during this interruption, and the $85^{\circ} \mathrm{C}$ signal point increased the most at $4-5 \mathrm{~h}$, indicating that the oil-paper insulation will be damaged quickly under high temperature conditions. Samples A and B were subjected to pressure for 7 time periods at normal $30^{\circ} \mathrm{C}$ and $50^{\circ} \mathrm{C}$, and the maximum discharge at the time of breakdown did not exceed 20000pc. At $85^{\circ} \mathrm{C}$ and $105^{\circ} \mathrm{C}$, there are 6 and 5 time periods, respectively. The maximum discharge capacity during the breakdown time period is $25000 \mathrm{pc}$ to $30000 \mathrm{pc}$, and the maximum discharge difference between high and low temperature is about $5000 \mathrm{pc}$ to $7000 \mathrm{pc}$.

Figure 3 (c) and (d) show the development trends of samples $\mathrm{A}$ and $\mathrm{B}$ in the middle and late stages of $85^{\circ} \mathrm{C}$ and $105^{\circ} \mathrm{C}$, respectively. Comparing the results of two different temperatures, it can be seen that the $105^{\circ} \mathrm{C}$ high temperature situation enters the rapid discharge development stage faster, and the maximum discharge capacity in the middle period is much higher than $85^{\circ} \mathrm{C}$, and the maximum discharge capacity is about the same at the two temperatures in the late discharge ; Comparing the two samples, it can be seen that from $3 \mathrm{~h}$ to $5 \mathrm{~h}$ in the middle period, the maximum discharge capacity of sample B increases more than A, and it enters a high discharge capacity state earlier and has a longer duration. According to Table 1, it can be seen that during the final breakdown The sample B withstand voltage time is shorter than that of sample $\mathrm{A}$, so the maximum discharge

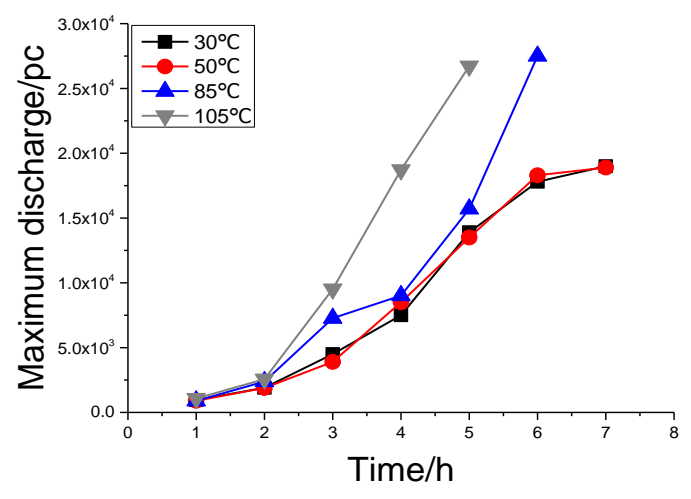

( a ) Maximum discharge capacity--sample A 


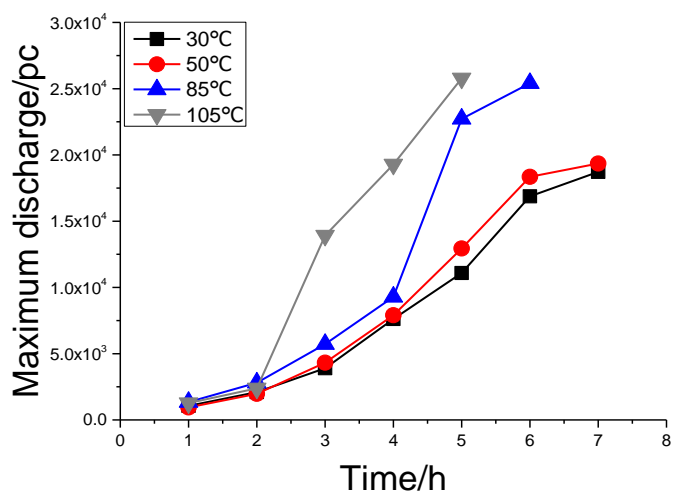

( b ) Maximum discharge capacity--sample B

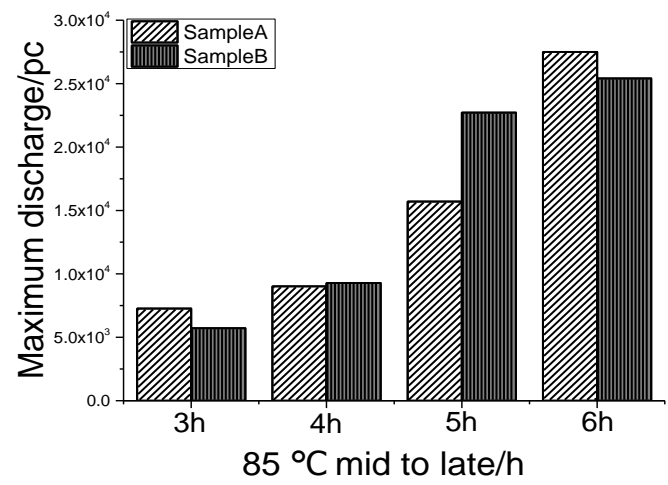

(c ) Maximum discharge capacity-mid to late discharge at $85^{\circ} \mathrm{C}$

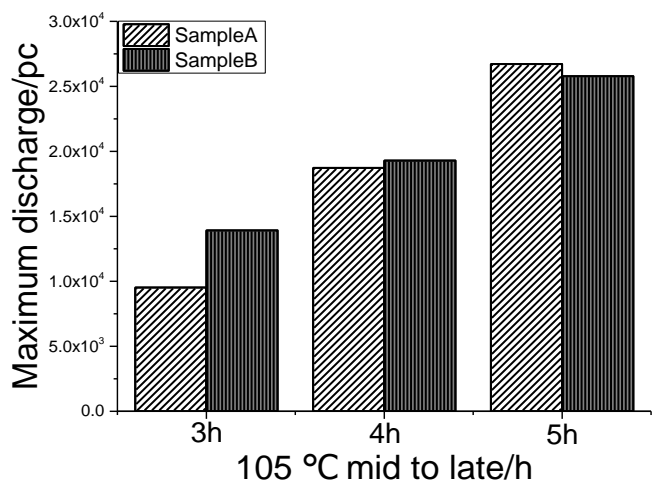

( d ) Maximum discharge capacity-mid to late discharge at $105{ }^{\circ} \mathrm{C}$

Fig.3 Maximum discharge capacity

of sample B during the $6 \mathrm{~h}$ period may be lower than that of sample A in the same period.

In summary, under normal temperature, the maximum discharge capacity gradually increases with the increase of the pressing time, and the maximum increase is reached at $3-5 \mathrm{~h}$ at high temperature, and the high discharge capacity withstand voltage is longer under high temperature. Comparing samples A and B, it can be seen that there is no significant difference in the maximum discharge capacity of samples A and B in the early stage of discharge. When it develops to the later stage of discharge, due to the long duration of high discharge in the middle stage, its breakdown time ends quickly, and sample B The maximum discharge is slightly smaller than that of sample A.

\section{B. Comparison of average discharge}

Figures 4 (a) and (b) show the average discharge of samples A and B at four temperatures. Between $1 \mathrm{~h}$ and $4 \mathrm{~h}$ of discharge, the average discharges at $30^{\circ} \mathrm{C}, 50^{\circ} \mathrm{C}$, and $85^{\circ} \mathrm{C}$ all showed a gentle growth trend, while the average discharge of Sample B increased sharply to $7000 \mathrm{pc}$ at 3 hours at $105^{\circ} \mathrm{C}$, which is the other three temperatures. About 2.5 times and about 1.5 times that of sample A under the same conditions. After entering the last $5 \mathrm{~h}\left(4\right.$ hours at $\left.105^{\circ} \mathrm{C}\right)$, the average discharge volume at each temperature has entered a high-speed increase state. Finally, the difference between the average discharge volume at $105^{\circ} \mathrm{C}$ and the other three temperatures is about $2000 \mathrm{pc}$ to $4000 \mathrm{pc}$, which is less than the maximum discharge volume gap. It can be seen that the gap between the average discharge volume at the other three temperatures during the breakdown period is slightly smaller.

Figures 4 (c) and (d) show the development trend of the average discharge of samples $\mathrm{A}$ and $\mathrm{B}$ at the middle and late stages of $85^{\circ} \mathrm{C}$ and $105^{\circ} \mathrm{C}$.There is no big difference between samples A and B at $3 \mathrm{~h}$ and $4 \mathrm{~h}$.In the late $5 \mathrm{~h}$ period, the average discharge increase of Sample A at $85^{\circ} \mathrm{C}$ is much larger than that of Sample B, and it is basically the same at $105^{\circ} \mathrm{C}$. Considering that the breakdown temperature of $105^{\circ} \mathrm{C}$ is only $0.5 \mathrm{~min}$, the breakdown voltage is only $0.5 \mathrm{~min}$. Here we choose the $6 \mathrm{~h}$ breakdown voltage at $85^{\circ} \mathrm{C}$ and the $5 \mathrm{~h}$ breakdown pressure at $105^{\circ} \mathrm{C}$. Near the breakdown stage, the average discharges of samples A and B under the two high-temperature conditions are about the same, about $16000 \mathrm{pc}$, and the average discharge is higher at $105^{\circ} \mathrm{C}$, reaching about $18000 \mathrm{pc}$.

In summary, with the increase of the pressing time, the average discharge of each sample at different temperatures continues to increase, and the average discharge at the time of final breakdown reaches about $16000 \mathrm{pc}$ to $18000 \mathrm{pc}$. At different temperatures and different paperboard samples, the difference in average discharge is smaller than the maximum discharge. Only

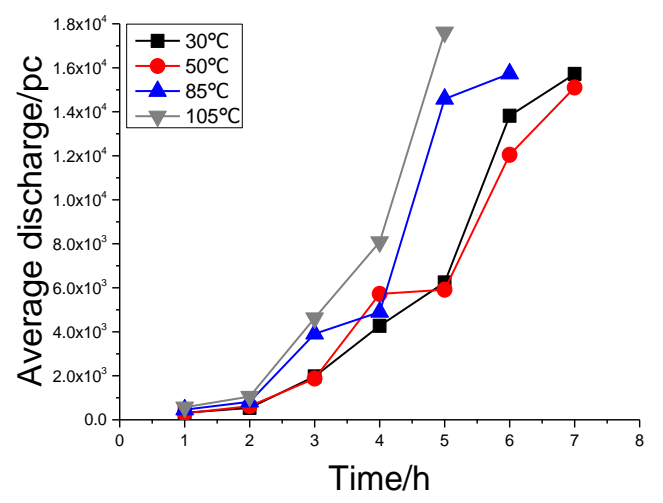

( a ) Average discharge-sample A 
ISSN: 2394-3661, Volume-7, Issue-3, March 2020

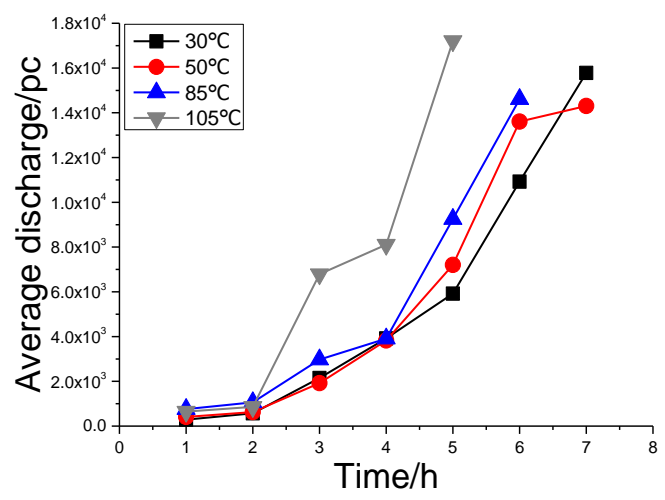

( b ) Average discharge-sample B

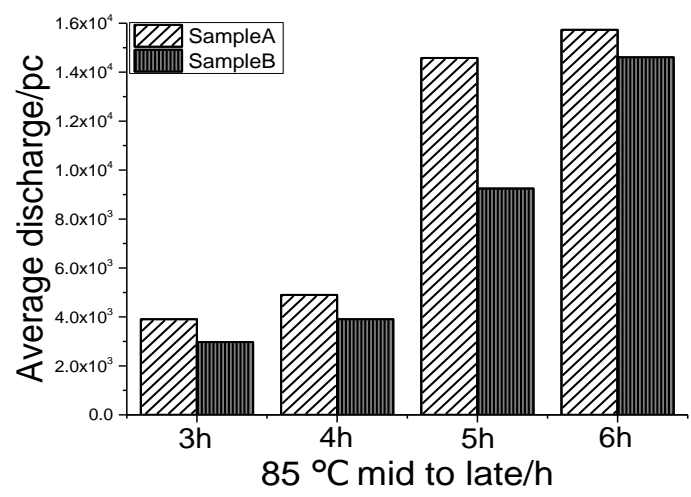

( c ) Average discharge capacity-mid to late discharge at $85^{\circ} \mathrm{C}$

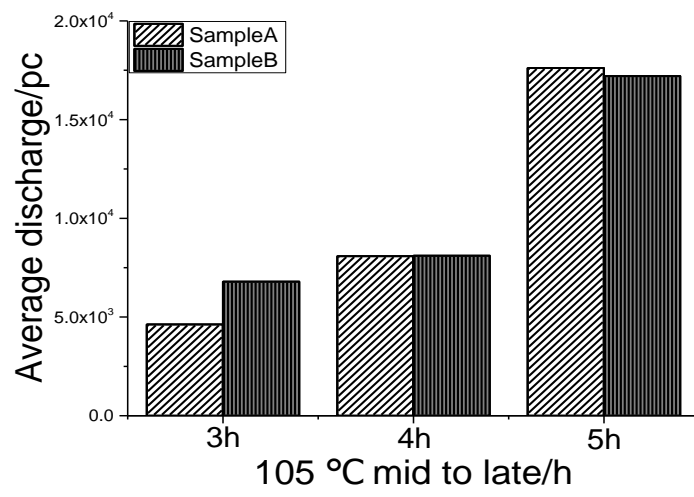

(d ) Average discharge capacity-mid to late discharge at $105^{\circ} \mathrm{C}$

Fig.4 Average discharge capacity

at $105^{\circ} \mathrm{C}$, sample $\mathrm{B}$ enters a high discharge and high increase state earlier.

\section{Comparison of discharge times}

Figures 5 (a) and (b) show the number of discharges of samples $\mathrm{A}$ and $\mathrm{B}$ at different temperatures. The discharge times of both samples increase with the increase of the pressing time, and the increase rate is about the same as the increase rate. However, the initial discharge times of sample B were about 100 to 200 times per hour more than that of sample $\mathrm{A}$, and the increase in discharge times at $3 \mathrm{~h}$ was significantly higher than other data points. Under normal temperature conditions, the number of discharges in the later stage of the discharge is smaller than the high temperature of $85^{\circ} \mathrm{C}$ and $105^{\circ} \mathrm{C}$. In view of the average discharge amount and the maximum discharge amount and the pressing time, it may be caused by a longer pressing time, Although the oil paper sample has a slightly smaller number of discharges, its overall discharge capacity is higher at $6 \mathrm{~h}$ and $7 \mathrm{~h}$, which is different from the $5 \mathrm{~h}$ time at normal temperature, which results in a longer time pressure resistance of the paperboard, which eventually causes the breakdown of the paperboard.

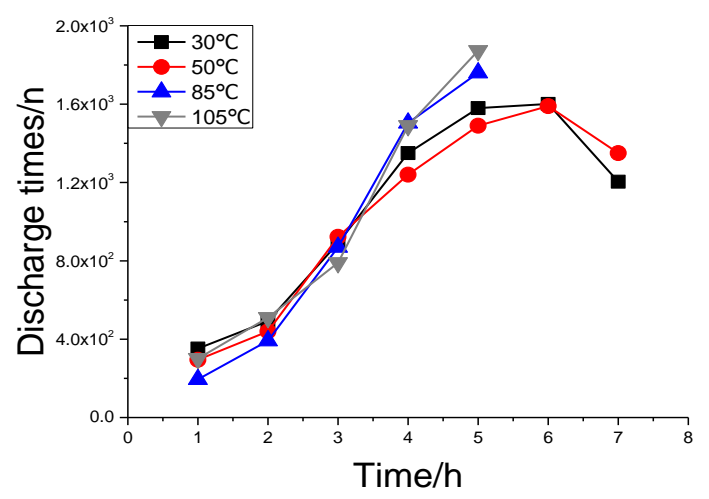

( a ) Discharge times-sample A

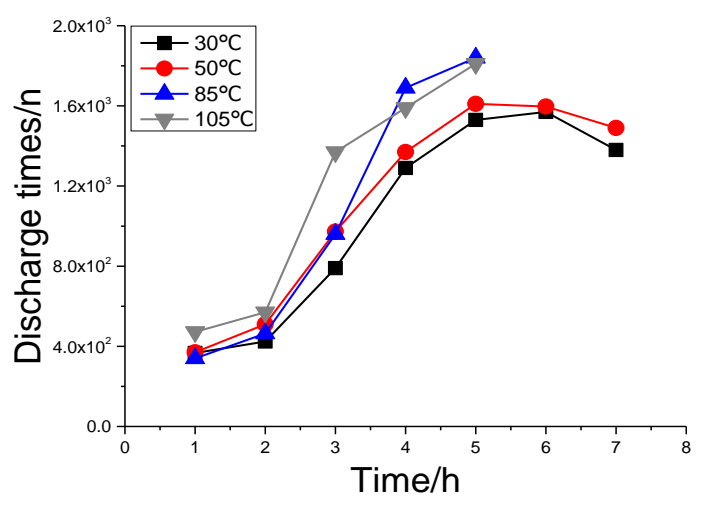

( b ) Discharge times-sample B

Fig.5 Number of discharges

Figures 6 (a) and (b) show the ratio of the number of discharges at each phase point of the phase spectrum when the two samples are pressurized to $1 \mathrm{~h}$ and $4 \mathrm{~h}$ at $30^{\circ} \mathrm{C}$ and $50^{\circ} \mathrm{C}$, respectively. Analysis based on 20000 times. With reference to Figure 5, it can be seen that under normal circumstances, there is no significant difference in the number of discharges of samples A and B. Therefore, Figures 6 (a) and (b) can represent the general laws of the two samples at normal temperatures without significant differences. The number of discharges is small at $1 \mathrm{~h}$, accounting for about $1 / 5$ of the maximum number of discharges, and the ratio of the number of discharges recorded to about 0.6-0.8 when it develops to $4 \mathrm{~h}$ 。 The main phase of the pin plate partial discharge is concentrated around $90^{\circ}, 270^{\circ}$, and the overall shape is a sharp wave. Figures 6 (c) and (d) are the ratios of the number of discharges of samples $A$ and $B$ at $105^{\circ} \mathrm{C}$ when the discharge develops to $5 \mathrm{~h}$. When it develops from $105^{\circ} \mathrm{C}$ to $3 \mathrm{~h}$, the number of discharges of sample B first enters the burst phase, which is about 0.3 percentage points higher than that of sample $A$ at this stage, and then 


\section{Development rule of temperature on oil-paper-insulated pin plate discharge under long-term operation Research}

the discharge times of both are about the same at $4 \mathrm{~h}$ and 5h. Therefore, the overall ratio of the number of discharges when sample $B$ is collected to $5 \mathrm{~h}$ in $(\mathrm{d})$ is slightly higher than the ratio of sample $\mathrm{A}$ in (c), and the ratio of the number of discharges near the phase of $90^{\circ}$ and $270^{\circ}$ is high Wider, the amplitude of the proportion of each phase point between 0.4 and 1 is mostly higher than that of sample A.
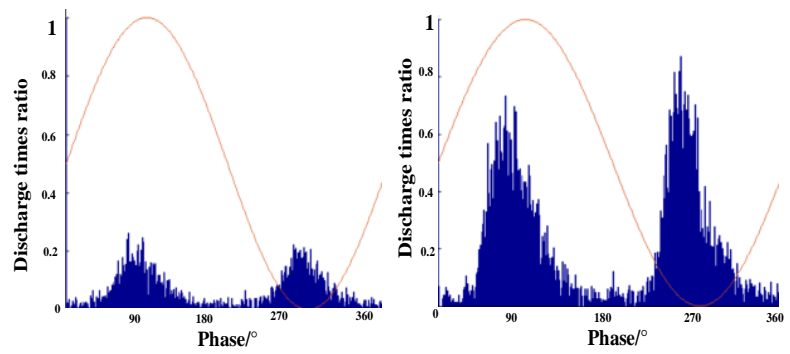

( a ) Low temperature ratio of $1 \mathrm{~h}$ ( b ) Low temperature ratio of $1 \mathrm{~h}$

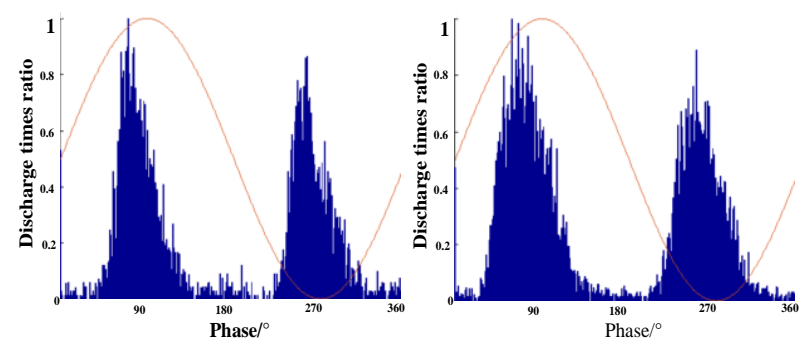

(c) Sample A ratio- $5 \mathrm{~h} / 105^{\circ} \mathrm{C} \quad$ (d ) Sample B ratio- $5 \mathrm{~h} / 105^{\circ} \mathrm{C}$

Fig.6 Discharge frequency ratio spectrum chart

\section{CONCLUSION}

In this paper, two types of oil-paper insulation samples that are simulated for thermal aging for 32 days and actual long-term operation are used as test objects. The oil-paper insulation needles are studied at four temperatures: $30^{\circ} \mathrm{C}, 50^{\circ} \mathrm{C}, 85^{\circ} \mathrm{C}$ signal point and $105^{\circ} \mathrm{C}$ trip point. Development characteristics of plate partial discharge, the conclusion is as follows:

1 ) There is no significant difference between the initial voltage and breakdown voltage of the two samples at normal temperature。 When the high temperature is from $85^{\circ} \mathrm{C}$ to $105^{\circ} \mathrm{C}$, the difference between the initial voltage of the two samples gradually increases, and the breakdown voltage of the two samples is significantly different. The oil-paper insulation sample B actually collected at $105^{\circ} \mathrm{C}$ entered the critical breakdown state earlier, and the breakdown voltage was significantly reduced;

2 ) At normal temperature, the maximum discharge and average discharge gradually increase with the increase of the pressing time, and the gap between the two samples is slightly smaller. When the discharge develops to the middle and late stages, the actual discharge capacity of the oil-paper insulation is gradually larger than the simulated aging sample, and the maximum difference is reached when it develops from $85^{\circ} \mathrm{C}$ to $105^{\circ} \mathrm{C}$;

3 ) The number of discharges of the two samples at different temperatures gradually increased with the increase of the pressing time, but the ratio of the number of discharges, the phase window width, and the density of the actual running samples at the later stage of high temperature discharge were larger than the simulated aging samples;

To sum up, at the signal point of about $85^{\circ} \mathrm{C}$, as the pressure time increases, the actual oil-paper insulation level declines faster than the laboratory simulated aging rate.In the actual work on site, except for the protection of the main transformer, human intervention is required when the oil temperature reaches $85^{\circ} \mathrm{C}$. When the transformer online monitoring device finds a large amount of discharge characteristics, it should be paid enough attention and manual prevention and treatment should be performed.Prevents maintenance operators and other personnel from reaching the high-temperature $105^{\circ} \mathrm{C}$ tripping phenomenon before reaching the site, which not only seriously damages the transformer insulation, but also may cause serious operating defects in the power grid.

\section{References}

[1] Tang Ju. Fundamental Research on Power Failure Caused by Insulation Fault in Transformer Protection Equipment[J]. High voltage technology,2012,06:1281-1291.

[2] Judd M D, Li Yang, Hunter I B. Partial discharge monitoring for power transformer using UHF sensors. part 2: field experience[J]. IEEE Electrical Insulation Magazine, 2005, 21(3): 5-13.

[3] Ping S, Xu D, Wang G, et al. Application of neural network with genetic algorithm to UHF PD pattern recognition in transformers[C]// Electrical Insulation and Dielectric Phenomena, 2002 Report Conference on. 2002:35.

[4] Brunt R J V, Cernyar E W, Glahn P V. Importance of unraveling memory propagation effects in interpreting data on partial discharge statistics[J]. IEEE Transactions on Electrical Insulation, 1993, 28(6):905-916

[5] Yu Rui, Gao Bo, Hu Guangcai, et al.White spot development and discharge characteristics of oil-paper insulated pin plate creeping discharge model.High voltage technology,2020,46(01):240-249.

[6] Wu Guangning, Zhou Fan, Gao Bo, et al.Development and discharge characteristics of surface discharge of oil-impregnated cardboard with different moisture contents[J/OL].Journal of Southwest Jiaotong University:1-9[2020-03-05].

[7] Li Xining, Ji Shengchang, Cui Yanjie, et al.Effect of DC Component in AC / DC Composite Voltage on Partial Discharge Characteristics of Oil-Paper Insulated Pin Board[J].High voltage technology,2019,45(12):3869-3878 .

[8] Li Simeng.Research on the Influence of Converter DC Electric Field Component on the Partial Discharge Characteristics of Oil-Paper Insulated Pin Board and Its Discharge Mechanism[D].Shan Dong University,2019 .

[9] Lv Fangcheng, Liu Xiaobin, Xie Jun, et al. Effect of cardboard aging on discharge of oil-paper insulation pin plate[J].Insulation Materials,2017,50(01):49-54 .

[10] Zhou Yuanxiang, Dai Chao, Huang Meng, et al. Influence ofaging temperature on thermal charge insulation space charge characteristics during thermal aging[J].High voltage technology,2016,42(03):868-875 